\title{
Neurochemical correlates of male polymorphism and alternative reproductive tactics in the Azorean rock-pool blenny, Parablennius parvicornis
}

\author{
Jason A. Miranda, ${ }^{\text {a,c }}$ Rui F. Oliveira, ${ }^{\mathrm{b}}$ Luis A. Carneiro, ${ }^{\mathrm{b}}$ Ricardo S. Santos, ${ }^{\mathrm{c}}$ \\ and Matthew S. Grober ${ }^{\mathrm{d}, *}$

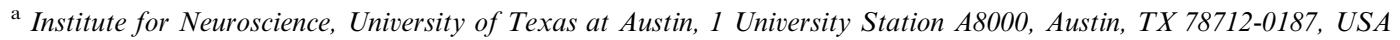 \\ ${ }^{\mathrm{b}}$ Unidade de Investigação em Eco-Etologia, Instituto Superior de Psicologia Aplicada, Rua Jardim do Tabaco 34, 1100 Lisboa, Portugal \\ ${ }^{\mathrm{c}}$ Departamento de Oceanografia e Pescas, Universidade dos Açores, 9901-862 Horta, Açores, Portugal \\ d Department of Biology, Georgia State University, 24 Peachtree Center Ave. NE, Atlanta, GA 30303, USA
}

Accepted 21 January 2003

\begin{abstract}
In the common Azorean rock-pool blenny, Parablennius parvicornis, males exhibit alternative reproductive morphologies: (1) larger males defend nest sites, provide parental care, have anal glands (involved in pheromone release), testicular glands, and low gonad:body weight ratio (GSI) and (2) smaller, younger, males do not defend nests, have reduced glands and high GSI. These smaller non-nesting males behave as satellites (associated with nests) or sneakers (moving among nests), attempting to achieve parasitic fertilizations via sperm competition. In non-mammals, arginine vasotocin (AVT) is a key hypothalamic peptide involved in the control of reproductive behavior and physiology, and several fish species that exhibit alternative male reproductive morphs show polymorphism in AVT brain chemistry. We conducted an immunocytochemical study to generate comparative data on this intertidal blenny. Our analysis showed no difference in AVT-immunoreactive cell number or size between the male morphs, which is consistent with studies on other fish, including blennies. The number of AVT cells was positively correlated to fish body mass, while cell size showed no such relation. If corrected for body mass, the smaller non-nesting males have significantly more cells than the large nesting males. Our data suggest that the size and number of forebrain AVT cells develops initially to allow for reproduction in the young non-nesting males and this pattern does not appear to change when males take on the nesting morphotype later in life. This result appears to be consistent in many fishes with alternative male morphotypes.
\end{abstract}

(C) 2003 Elsevier Science (USA). All rights reserved.

Keywords: Arginine vasotocin (AVT); Hypothalamus; Immunocytochemistry; Preoptic area; Satellite males; Sneaker males; Azores

\section{Introduction}

Competition for access to mates can generate alternative mating tactics to increase fitness, and this is well illustrated among fishes (Taborsky, 1994). The behavior and ecology of many such fishes has been well studied, but comprehensive studies of proximate mechanisms that govern alternative sex morphotypes are still uncommon. In early July, on the volcanic platforms that constitute the intertidal zone on the coast of the island

\footnotetext{
${ }^{*}$ Corresponding author. Fax: 1-404-651-3929.

E-mail address: mgrober@gsu.edu (M.S. Grober).
}

of Faial in the Azores, male Azorean rock-pool blennies (Parablennius parvicornis) begin their highly competitive breeding season. By the end of the reproductive season, males show a significant increase in injuries due to intraspecific aggression (Santos and Nash, 1996). Males exhibit a flexible alternative phenotype in which individuals may switch tactics during their lifetime. Large older males (total length $\approx 14 \mathrm{~cm}$ and age $\geqslant 2$ years) compete for nest sites where they attract females for mating. Small younger males (total length $\approx 10 \mathrm{~cm}$ and age $\approx 1$ year) compete by adopting one of two parasitic tactics: (1) satellite or (2) sneaker. For the rest of this report we will refer to the smaller males as non-nesting. 
Parental care is exhibited by the nesting male, including nest defense against non-nesting males (Santos and Barreiros, 1993; Santos et al., 1995, 1996). As a first approach to elucidating the mechanisms that generate alternative reproductive behavior, Oliveira et al. (2001) report differences in plasma androgen levels between the two male morphotypes. In this study, we investigate the neurochemical traits associated with the behavioral and morphological differentiation of the alternative mating tactics in P. parvicornis.

Arginine vasotocin (AVT) is a peptide hormone produced in the hypothalamus and released in the brain and blood in fish, amphibians, reptiles, birds, and fetal mammals. This peptide is an ancestral form of arginine vasopressin (AVP), found in mammalian vertebrates, and differs only by one amino acid in the third position (AVT containing Ile and AVP containing Phe) (Moore, 1992). Both AVT and AVP have been shown to affect the behavior and reproductive physiology of vertebrates, including smooth muscle contraction of the reproductive tract and activity of cells lining mammary glands, as well as parental care and calling behavior (Moore, 1992). In amphibians, AVT injections (Propper and Dixon, 1997) and immunoreactivity (Marler et al., 1995) are associated with the regulation of calling and male mating amplexus. Administration of AVT has been reported to increase cloacal, somatic, and visual sensitivity in the rough skinned newt, Taricha granulosa (Rose et al., 1995). These animals also exhibit an AVT-induced increase in male clasping behavior.

Reproductive plasticity is common in teleosts and alternative reproductive tactics have been correlated with variation in AVT neurohistology, particularly of the preoptic area (POA), in a variety of fish species (Goodson and Bass, 2001). Male to female sex change is associated with changes in POA AVT cell size in the sequential hermaphroditic marine gobies, Trimma okinawae (Grober and Sunobe, 1996) and Lythrypnus dalli (Reavis and Grober, 1999). In the sex/role changing bluehead wrasse, Thalassoma bifasciatum, more aggressive and sexually dominant males have almost threefold higher AVT mRNA levels than females compared to the twofold higher levels in subordinate males (Godwin et al., 2000). In a teleost with male alternative mating tactics, Porichthys notatus, nesting males and females have fewer AVT-immunoreactive (AVT-ir) cells of the POA per gram of body mass than subordinate males (Foran and Bass, 1998). Similar results were found in the peacock blenny, Salaria pavo (George et al., 1999). A central role of AVT in the modulation of aggressive grunting has been demonstrated in P. notatus (Goodson and Bass, 2000a,b). There remains a need for further research into other comparable systems to add to the understanding of the central role of AVT in sex change and alternative reproductive tactics (Goodson and Bass, 2001).
Based upon our current understanding of the role of AVT in teleost reproductive behavior and previous data on sexual plasticity in $P$. parvicornis, we hypothesized that the number and/or size of AVT-ir cells of the POA would differ between morphotypes. We also hypothesized that the differences would correlate with differences in aggression and parental behavior that are exhibited by the morphotypes.

\section{Methods}

\subsection{P. parvicornis tagging and behavioral observations}

A detailed description of the behavioral observations for this study have been reported in Oliveira et al. $(2000,2001)$ thus a summary will be given here. Behavioral data for this study were collected during low tide in July 1999 in the tide pools at Fateira on the south coast of Faial Island, Azores $\left(38^{\circ} 31^{\prime} \mathrm{N}\right.$ and $28^{\circ} 27^{\prime} \mathrm{W}$ ). The distribution of the observations during the day ranged from 09:33 to 19:36 h. Strong wave action impeded observation during high tide. In order to elucidate the behavioral correlates of the alternative mating tactics, animals were identified and observed in their natural environment. P. parvicornis were captured from large isolated pools and tagged with a combination of three small colored beads as described by Patzner (1984). These beads were often identifiable with the unaided eye and binoculars were used when needed. Pools and pool areas were mapped using landmark characteristics to record daily position within the pool and time spent near nests for each animal. Nesting males clean and actively defend nest areas therefore each nest was mapped as the clean area defended by a single male. Each observation period lasted 20 min with an average of three observations per individual on different days (minimum $20 \mathrm{~min}$, maximum $180 \mathrm{~min}$, and mean $86.5 \mathrm{~min}$ ). We recorded the following behavior patterns: frequency of interspecific charge, number of quivering events (spawning), frequency and duration of territory approaches, and frequency of sneaking attempts. The detailed ethogram of $P$. parvicornis is reported by Santos and Barreiros (1993). These data were then used to categorize males as either nesting males or non-nesting males. Total body mass of the individual and gonad mass were recorded after all observations were complete in order to further strengthen the validity of the morphotype categorizations (Oliveira et al., 2000).

\subsection{Immunocytochemistry for AVT-ir cells}

After we completed the observations, all animals were recaptured with handnets, anesthetized with MS222 (tricanemethane sulfonate, Sigma Chemical), and the 
entire body was fixed by transcardial perfusion with $4 \%$ paraformaldehyde in ringer's solution. The brain was removed and placed in 4\% paraformaldehyde and stored at $4{ }^{\circ} \mathrm{C}$ for 7 days. The brains were then transferred to $0.1 \mathrm{M}$ phosphate buffer (PB) and stored at $4{ }^{\circ} \mathrm{C}$. Prior to sectioning with a cryostat the samples were saturated with $30 \%$ sucrose in PB. Sections were cut at $30 \mu \mathrm{m}$ in three series. Sections were thaw mounted on chromalum subbed slides and stored at $-20{ }^{\circ} \mathrm{C}$. One series from each animal was used for immunocytochemistry. All steps took place at room temperature unless otherwise noted. Slides were first defrosted then dried and blotted with filter paper. Sections were washed by soaking in $0.1 \mathrm{M} \mathrm{PB}$ for $7 \mathrm{~min}$ twice. Sections were then soaked for $20 \mathrm{~min}$ in presoak solution consisting of $2.8 \%$ normal goat serum, $4 \times 10^{-4 \%} \%$ Triton-X and $24.97 \%$ PB. Sections were then incubated with 1:750 dilution of rabbit anti-AVT primary antibody overnight at $4{ }^{\circ} \mathrm{C}$. Day 2 began with two 7-min washes in $0.1 \mathrm{M}$ PB before soaking in goat anti-rabbit secondary antibody for $30 \mathrm{~min}$. Two more 7-min PB washes were followed by the application of Streptavidin-Peroxidase (KPL) for $30 \mathrm{~min}$. The sections were washed twice again for $7 \mathrm{~min}$ in $\mathrm{PB}$ before the application of diaminobenzidine (DAB). Slides were exposed to DAB for about $5 \mathrm{~min}$ or until golden brown. The slides were then dehydrated with increasing concentrations of ethanol and xylene and coverslipped with permount.

\section{Cell quantification}

All slides were coded so that the individual who quantified the number and size of cells did not know the identity of the fish to which each slide corresponded. Cell number was counted by visual inspection of the tissue using a microscope. Cell size was measured by capturing images and tracing the outside margin of the soma using NIH Image 1.62a (W. Rasband, NIH, Bethesda, MD). After calibrating for magnification, the imaging program provided a measure of the area of each cell. A pilot study found that there was no significant difference between the right and left hemispheres of the brain with regard to AVT-ir cell number and cell size ( $n=6$ brains; cell number: $p=0.2391$; and cell size: $p=0.7882$ ). Therefore, we measured $20 \%$ of all parvocellular, magnocellular, and gigantocellular cells of the POA selected haphazardly from either the right or left hemisphere of the brain for each fish. Parvocellular, magnocellular, and gigantocellular neurons could be categorized based upon their size, dorsoventral, and rostrocaudal locations (see Braford and Northcutt, 1983 for neuroanatomical details). Differences in sample sizes between cell number and cell area analyses result form some animals having at least one missing section so cell counts were not possible. However, it was possible to estimate cell sizes for these animals and these data were included in the analysis.

\section{Statistical analysis}

Differences among the morphotypes with regard to behavior, body mass, gonadosomatic index (GSI: body mass (g)/gonad mass (g)), AVT-ir cell number, and cell size were determined using the Kruskal-Wallis test for significance. Non-parametric tests were used because these data did not satisfy the assumptions for ANOVA. Post-hoc comparisons were conducted with Mann-Whitney $U$ tests. Relationships between body size and cell size were examined using simple linear regression.

\section{Results}

\subsection{Morphotype categorization}

Morphotype categories were nesting male $(n=7)$, non-nesting male $(n=13)$, or female $(n=10)$, based on behavioral observations, bodymass data, and gonad morphology. Non-nesting males attempted parasitic fertilizations during six of the eight spawnings observed. Total body mass was significantly different between nesting and non-nesting males $[p<0.001$; mean \pm SD (n): nesting $=20.2 \pm 6.5 \mathrm{~g}$ (7); and non-nesting $=8.4 \pm$ $4.3 \mathrm{~g}$ (13)]. Female body mass was not significantly different from either of the male morhpotypes [13.95 \pm $5.56 \mathrm{~g}(6)]$. GSI was also significantly different between nesting and non-nesting males $[p=0.003$; mean \pm SD $(n)$ : nesting $=0.88 \pm 0.20 \mathrm{~g}$ (7); and non-nesting $=$ $3.40 \pm 1.91 \mathrm{~g}(13)]$.

\subsection{Neuroanatomical location of AVT POA cells in P. parvicornis}

The AVT-ir cell populations in this blenny are quite similar to those described for the plainfin midshipman (Foran and Bass, 1998) and peacock blenny (George et al., 1999). The parvocellular component is the most anterior and ventral and consists of relatively small (see below) and densely packed cells (Fig. 1). It begins on the ventral surface of the forebrain, dorsal to the optic chiasm, and moves dorso-caudally until giving way to the magnocellular component. The magnocellular neurons are positioned dorsal and caudal relative to the parvocellular cells, and are larger (see below) and less densely packed. The gigantocellular neurons are located dorsal and caudal to the magnocellular neurons and are the largest cells (see below) but are relatively few in number and sparsely distributed. 


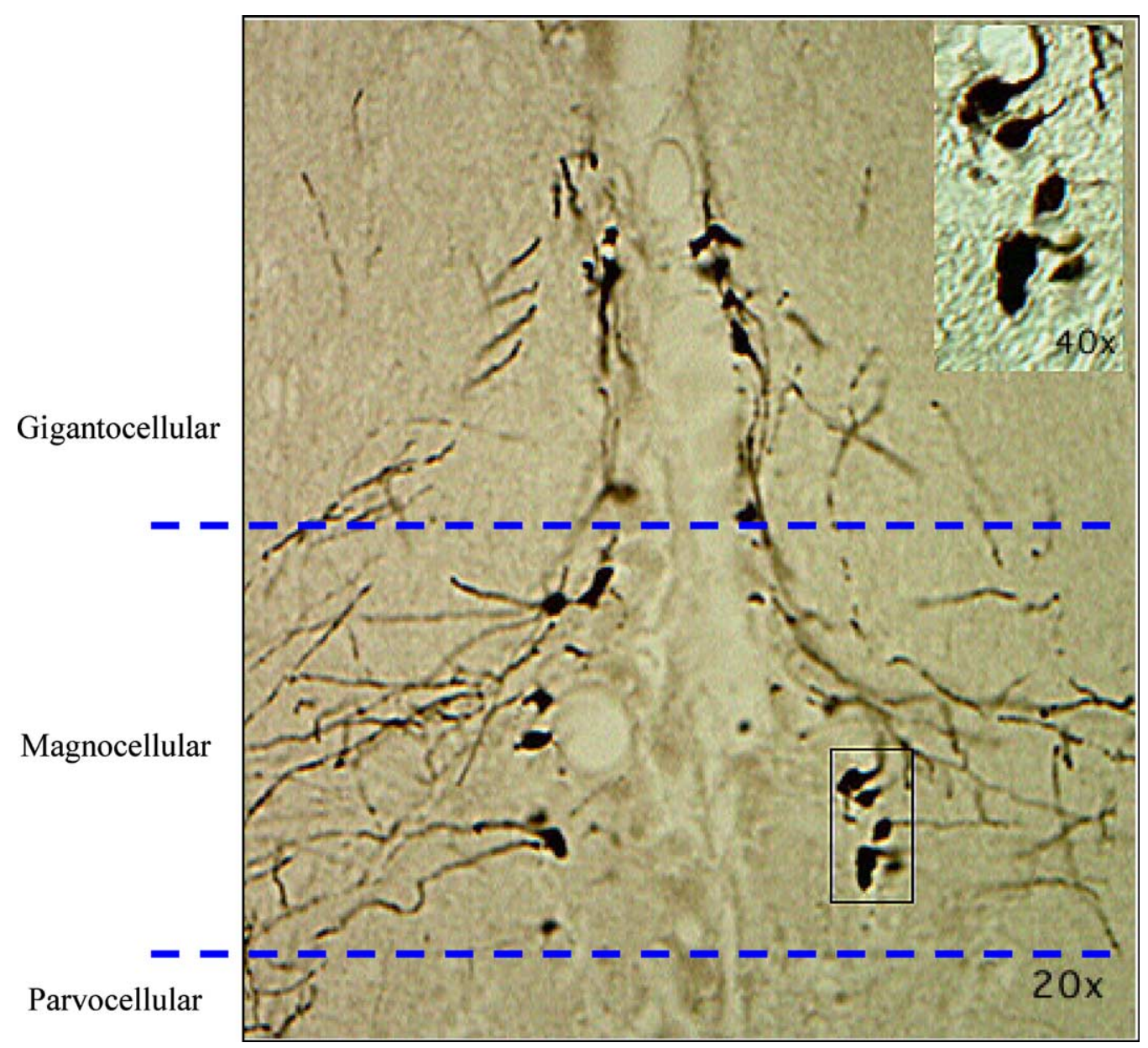

Fig. 1. A cross section of the forebrain of P. parvicornis. Dashed lines provide an approximate delineation of three divisions of the preoptic area of the hypothalamus as identified in this study. See text for details.

\subsection{Comparison of total AVT-ir cell number among nesting males, non-nesting males, and females}

There were no significant differences among the groups for number of AVT-ir cells within each of the POA populations (Table 1). On this basis, cells from all three areas were grouped for further analysis. No significant difference was found between the groups with regard to total cell number (Fig. 2A, $p=0.624$ ). Total cell number was positively correlated with body mass (Fig. 2B, $R^{2}=0.456, p=0.006$ ). Considering the differences in body mass between the two male morphotypes, cell number corrected for body mass was compared for all three groups. When corrected for body mass, non-nesting males show significantly more cells per gram (Fig. 2C, $p=0.025$ ). Although this approach to controlling for differences in body size between treatment groups is not optimal (ANCOVA is the most

Table 1

Number and size of AVT-immunoreactive cells in each of the major subdivisions of the preoptic area in the three reproductive morphs of the Azorean rock-pool blenny, Parablennius parvicornis

\begin{tabular}{lllll}
\hline Morph trait & Nesting males & Non-nesting males & Females & $p$ value \\
\hline Parvocelluar number & $101.75 \pm 18.36$ & $84.4 \pm 24.37$ & $82.5 \pm 32.32$ & 0.88 \\
Magnocelluar number & $68.0 \pm 36.14$ & $44.0 \pm 10.27$ & $55.5 \pm 11.41$ & 0.48 \\
Gigantocelluar number & $21.25 \pm 2.36$ & $26.2 \pm 4.33$ & $6.6 \pm 73.47$ & \\
Sample size $(N)$ & 4 & 5 & $31.94 \pm 6.81$ & 0.43 \\
Parvocelluar size & $35.22 \pm 3.57$ & $35.88 \pm 1.60$ & $61.33 \pm 7.57$ & 0.78 \\
Magnocelluar size & $53.72 \pm 4.84$ & $48.95 \pm 4.3$ & $125.12 \pm 13.09$ & 0.31 \\
Gigantocelluar size & $114.34 \pm 6.44$ & $105.96 \pm 11.55$ & 6 & 0.47 \\
Sample size $(N)$ & 7 & 8 & & \\
\hline
\end{tabular}

Values are the means \pm SEM. 


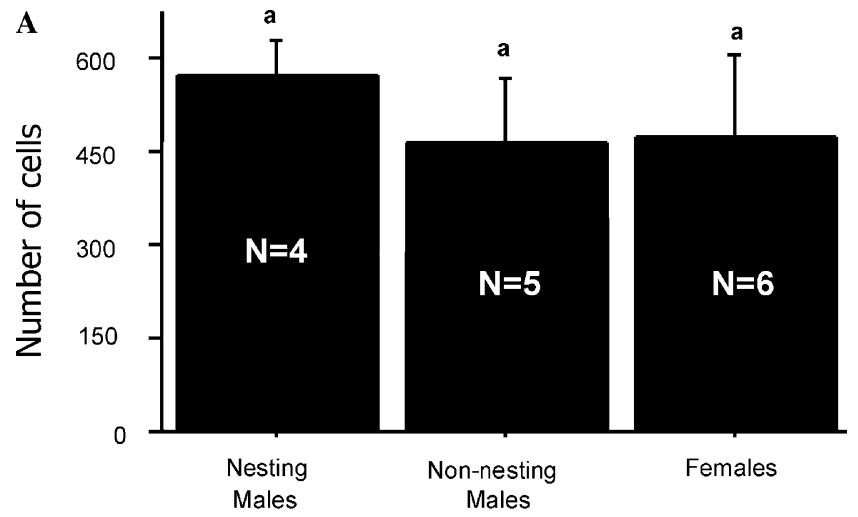

B

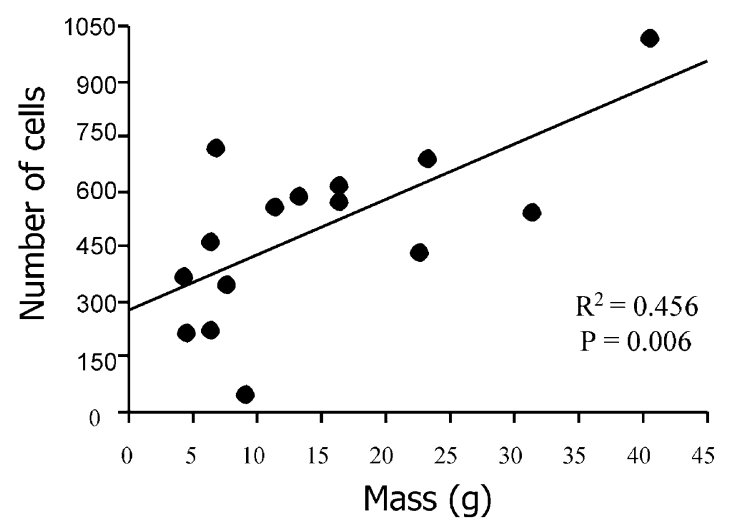

C

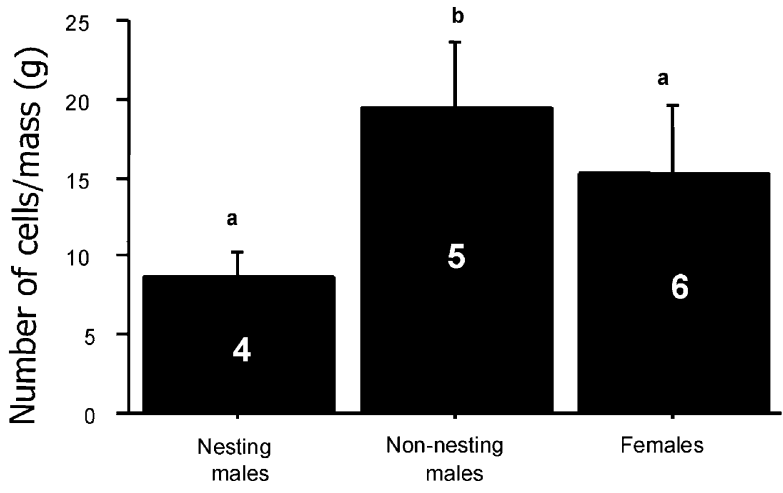

Fig. 2. Bars represent average number of cells for each morphotype $( \pm$ SEM). Numbers within each bar are sample sizes. Bars sharing a common letter are not statistically different $(p>0.05)$. (A) Total number of cells was compared between the two male morphotypes and the females. (B) Number of cells is plotted against the individual's mass. (C) A comparison of the mass-corrected cell number.

appropriate analysis), our data did not meet the assumptions for that test, since the slopes of body size vs cell size and/or number for the different reproductive morphs are not parallel. However, we did show a significant overall effect of body size on AVT cells and as such need to control for body size when comparing reproductive morphs. Our method (to divide brain cell characteristics by body size) has been used in previous studies examining brain cells in sexually polymorphic fish and provided novel insights into the development of male alternative reproductive phenotypes (Grober et al., 1994, 2002).

\subsection{Comparison of average AVT-ir cell size among nesting males, non-nesting males, and females}

There were no significant differences among the groups for size of AVT-ir cells within each of the POA populations (Table 1). On this basis, cells from all three
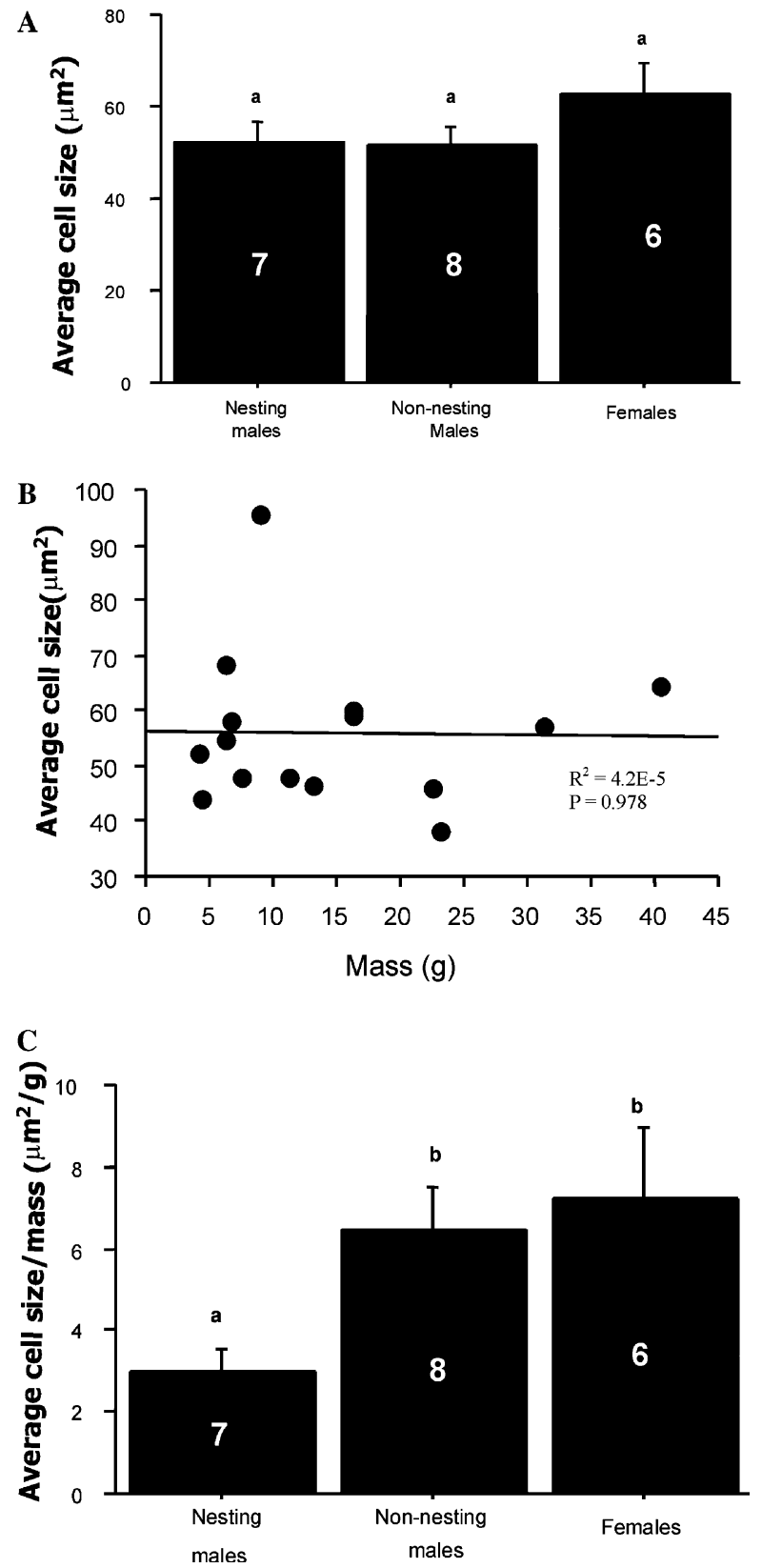

Fig. 3. Bars represent average cell size for each morphotype ( \pm SEM). Numbers within each bar are sample sizes. Bars sharing a common letter are not statistically different $(p>0.05)$. (A) Average cell size is compared between the two male morpotypes and the females. (B) Average cell size is plotted against the individual's mass. (C) A comparison of the mass corrected average cell size. 
areas were grouped for further analysis. Again no significant differences were found among the morphotypes in cell size (Fig. 3A, $p=0.907$ ). No correlation was found between cell size and body mass for all fish (Fig. $\left.3 \mathrm{~B}, R^{2}=4.2 \times 10^{-5}, p=0.978\right)$. A significant difference, however, was found when comparing mass corrected cell size with non-nesting males having significantly larger cells per gram than nesting males (Fig. 3C, $p=0.028$ ).

A comparison among morphs was carried out within each of the three regions of the preoptic area (parvocellular, magnocellular, and gigantocellular) to determine the source of variation found in the mass corrected data. The parvocellular, magnocellular, and gigantocellular regions all showed significantly larger mass

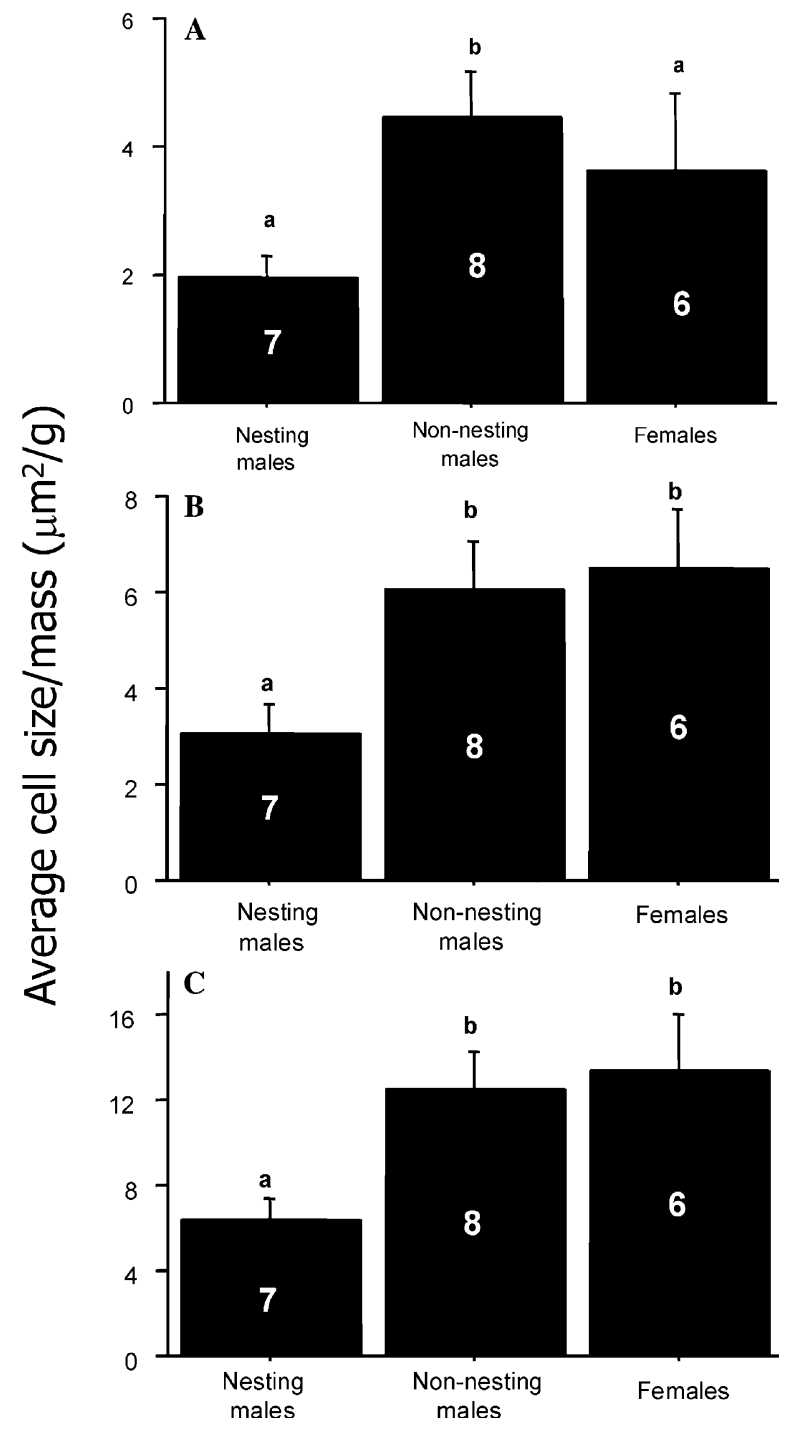

Fig. 4. Bars represent average cell size for each morphotype ( \pm SEM). Numbers within each bar are sample sizes. Bars sharing a common letter are not statistically different $(p>0.05)$. Average cell size corrected for mass was compared between the two male morphotypes and the females for the (A) parvocellular, (B) magnocellular, and (C) gigantocellular regions of the preoptic area. corrected cell size in the non-nesting male morphotype (Figs. 4A-C, parvo $p=0.011$, magno $p=0.049$, and giganto $p=0.028$ ). These results show that all three regions contribute to the variation in mass corrected average cell size.

\section{Discussion}

These results are consistent with results found in other fish species (Foran and Bass, 1998) including blennies (Grober et al., 2002). Recent AVT injection studies in other telosts have provided insight into the role of this neuropeptide in the modulation of aggression and courtship. Intracerebroventricular injection of AVT in the white perch, Morone americana, increased the primary courtship behavior of males (Salek et al., 2002). In the weakly electric fish, Apteronotus leptorhynchus, AVT injection increased chirps consistent with those made during courtship and mating while decreasing the production of agonistic chirps (Bastian et al., 2001). In the tropical coral reef fish, T. bifasciatum, AVT increased courtship and decreased aggressive behavior in dominant territorial males while increasing courtship, aggressive, and territorial behavior in subordinate males that otherwise mimic females (Semsar et al., 2001). This result shows a different effect of AVT on behavior at different points during the reproductive life of males in T. bifasciatum. Given the results of studies in other teleost fishes and the data presented in this study, AVT appears to play a role in regulating the reproductive phenotype of male $P$. parvicornis.

\section{Acknowledgments}

We thank A. George for assistance with image analysis, G. Schuett, M. Burleson and to the Grober lab reading group for helpful comments. This work was supported by the Arizona State University NIH-MARC Program, Fundação para a Ciência e a Tecnologia, FEDER (PRAXIS XXI, PCNA/BIA/94/96) and NSF (IBN-9723817). We dedicate this paper to the loving memory of Luis Alberto Carneiro whose tragic loss we suffered over the course of this work.

\section{References}

Bastian, J., Schniederjan, S., Nguyenkim, J., 2001. Arginine vasotocin modulates a sexually dimorphic communication behavior in the weakly electric fish Apternotus leptorhynchus. J. Exp. Biol. 204, 1909-1923.

Braford, M.R.J., Northcutt, R.G., 1983. Organization of the diencephalon and pretectum of the ray-finned fishes. In: Northcutt, R.G., Davis, R.E. (Eds.), Fish Neurobiology, vol. 2. University of Michigan Press, Ann Arbor, MI, pp. 117-163. 
Foran, C.M., Bass, A.H., 1998. Preoptic AVT immunoreactive neurons of a teleost fish with alternative reproductive tactics. Gen. Comp. Endocrinol. 111, 271-282.

George, A.A., Watkins, K.K., Carneiro, L.A., Oliveira, R.F., Grober, M.S., 1999. Courtship in a sexually polymorphic fish: the role of vasotocin and gonadal steroids. Soc. Neurosci. Abst. 25, 74.

Godwin, J., Sawby, R., Warner, R.R., Crews, D., Grober, M.S., 2000. Hypothalamic arginine vasotocin mRNA abundance variation across sexes and with sex change in a coral reef fish. Brain Behav. Evol. 55, 77-84.

Goodson, J.L., Bass, A.H., 2000a. Forebrain peptides modulate sexually polymorphic vocal circuitry. Nature 403, 769-772.

Goodson, J.L., Bass, A.H., 2000b. Vasotocin innervation and modulation of vocal-acoustic circuitry in the teleost Porichthys notatus. J. Comp. Neurol. 422, 363-379.

Goodson, J.L., Bass, A.H., 2001. Social behavior functions and related anatomical characteristics of vasotocin/vasopressin systems in vertebrates. Brain Res. Rev. 35, 246-265.

Grober, M.S., Sunobe, T., 1996. Serial adult sex change involves rapid and reversible changes in forebrain neurochemistry. Neuroreport 7 , 2945-2949.

Grober, M.S., Laughlin, C., Fox, S., Bass, A., 1994. GnRH cell size and number in a teleost fish with two male reproductive morphs: sexual maturation, final sexual status and body size allometry. Brain Behav. Evol. 43, 61-78.

Grober, M.S., George, A.A., Watkins, K.K., Carneiro, L.A., Oliveira, R.F., 2002. Forebrain AVT and courtship in a fish with male alternative reproductive tactics. Brain Res. Bull. 57, 423-425.

Marler, C.A., Chu, J., Wilczynski, W., 1995. Arginine vasotocin injection increases probability of calling in cricket frogs, but causes call changes characteristic of less aggressive males. Horm. Behav. 29, 554-570.

Moore, F.L., 1992. Evolutionary precedents for behavioral actions of oxytocin and vasopressin. Ann. NY Acad. Sci. 652, 156-165.

Oliveira, R.F., Canario, A.V., Grober, M.S., Santos, R.S., 2001. Endocrine correlates of male polymorphism and alternative reproductive tactics in the Azorean rock-pool blenny, Parablennius sanguinolentus parvicornis. Gen. Comp. Endocrinol. 121, $278-288$.

Oliveira, R.F., Miranda, J.A., Carvalho, N., Gonçalves, E.J., Grober, M.S., Santos, R.S., 2000. Male mating success in the Azorean rockpool blenny: the effects of body size, male behaviour, and nest characteristics. J. Fish Biol. 57, 1416-1428.

Potzner, R.A., 1984. Individual tagging of small fish. Aquaculture 40, 251-253.

Propper, C.R., Dixon, T.B., 1997. Differential effects of arginine vasotocin and gonadotropin-releasing hormone on sexual behaviors in an anuran amphibian. Horm. Behav. 32, 99-104.
Reavis, R.H., Grober, M.S., 1999. An integrative approach to sex change: social, behavioural, and neurochemical changes in Lythrypnus dalli (Pisces). Acta Ethologica 2, 51-60.

Rose, J.D., Kinnaird, J.R., Moore, F.L., 1995. Neurophysiological effects of vasotocin and corticosterone on medullary neurons: implications for hormonal control of amphibian courtship behavior. Neuroendocrinology 62, 406-417.

Salek, S.J., Sullivan, C.V., Godwin, J., 2002. Arginine vasotocin effects on courtship behavior in male white perch (Morone americana). Behav. Brain Res. 133 (2), 177-183.

Santos, R.S., Barreiros, J.P., 1993. The ethogram of Parablennius sanguinolentus parvicornis (Pisces: Blenniidae) from the Azores. Arquipélago. Life Mar. Sci. 11A, 73-90.

Santos, R.S., Nash, R.D.M., Hawkins, S.J., 1995. Age, growth and sex ratio of the Azorean rock-pool blenny, Parablennius sanguinolentus parvicornis. J. Mar. Biol. Assoc. UK 75 (3), 751-754.

Santos, R.S., Nash, R.D.M., 1996. Seasonal variations of injuries suffered by individuals of the Azorean rock pool blenny (Parablennius sanguinolentus parvicornis). Copeia 1, 216-219.

Santos, R.S., Hawkins, S.J., Nash, R.D.M., 1996. Reproductive phenology of the Azorean rock-pool blenny, a fish with alternative mating tactics. J. Fish Biol. 48 (5), 842-858.

Semsar, K.A., Kandel, F.L.M., Godwin, J., 2001. Manipulations of the AVT system shift social status and related courtship and aggressive behavior in the bluehead wrasse. Horm. Behav. 40, 21-31.

Taborsky, M., 1994. Sneakers, satellites and helpers: parasitic and cooperative behavior in fish reproduction. Adv. Stud. Behav. 23, $1-100$.

\section{Further reading}

Crews, D., 1992. Diversity of hormone-behavior relations in reproductive behavior. In: Becker, J.B., Breedlove, S.M., Crews, D. (Eds.), Behavioral Endocrinology. The MIT Press, Cambridge, MA, pp. 143-186.

Mahlmann, S., Meyerhof, W., Hausmann, H., et al., 1994. Structure, function, and phylogeny of $\left[\mathrm{Arg}^{8}\right]$ vasotocin receptors from teleost fish and toad. Proc. Natl. Acad. Sci. USA 91, 1342-1345.

Moore, F.L., 1998. Comparative neuroanatomy of vasotocin and vasopressin in amphibians and other vertebrates. Comp. Biochem. Physiol. C-Pharmacol. Toxicol. Endocrinol. 119, 251-260.

Peter, R.E., Fryer, J.N., 1983. Endocrine functions of the hypothalamus of ctinopterygians. In: Northcutt, R.G., Davis, R.E. (Eds.), Fish Neurobiology, vol. 2. University of Michigan Press, Ann Arbor, MI, pp. 165-201. 